\begin{tabular}{|c|c|c|c|}
\hline \multirow{3}{*}{$\begin{array}{r}\text { Case Reports in } \\
\text { Gastroenterology }\end{array}$} & \multicolumn{2}{|c|}{ Case Rep Gastroenterol 2016;10:459-465 } & \multirow[b]{2}{*}{$\begin{array}{l}\text { Karger } \\
\text { Open access }\end{array}$} \\
\hline & $\begin{array}{l}\text { DOI: 10.1159/000448133 } \\
\text { Publisnea onmine: August 31, } 2016\end{array}$ & $\begin{array}{l}\text { (c) } 2016 \text { The Author(s) } \\
\text { Published by S. Karger AG, Basel } \\
\text { www.karger.com/crg }\end{array}$ & \\
\hline & $\begin{array}{l}\text { This article is licensed under the } \\
\text { International License (CC BY-NC) } \\
\text { Usage and distribution for commer }\end{array}$ & $\begin{array}{l}\text { mons Attribution-NonCommercia } \\
\text { rger.com/Services/OpenAccessLice } \\
\text { quires written permission. }\end{array}$ & \\
\hline
\end{tabular}

\title{
Therapeutic Depletion of Iron Stores Is Not Associated with a Reduced Hemoglobin Mass in a Hemochromatosis Patient
}

\author{
Nina Wrobel Torben Pottgiesser Philipp Birkner Peter Deibert \\ Christoph Ahlgrim \\ Institute for Exercise und Occupational Medicine, University Medical Center Freiburg, \\ Faculty of Medicine, University of Freiburg, Freiburg, Germany
}

\section{Keywords}

Hemochromatosis · Iron overload · Phlebotomy · Total hemoglobin mass

\begin{abstract}
Introduction: Hereditary hemochromatosis features a dysregulated iron absorption leading to iron overload and organ damage. The regulation of total hemoglobin mass during depletion of iron deposits by therapeutic phlebotomy has not been studied. Case Presentation: The initial ferritin level of the 52-year-old male subject was $1,276 \mu \mathrm{g} / \mathrm{l}$. Despite successful depletion of iron stores (ferritin $\min : 53 \mu \mathrm{g} / \mathrm{l}$ ) through phlebotomies, total hemoglobin mass stabilized at the pretherapy level. However, regeneration of total hemoglobin mass was accelerated (up to $10.8 \mathrm{~g} / \mathrm{day}$ ). Conclusion: In this hemochromatosis patient, the total hemoglobin mass was not altered in the long term, but regeneration was accelerated, possibly due to elevated body iron content.

(C) 2016 The Author(s)

Published by S. Karger AG, Basel
\end{abstract}

\section{Introduction}

Hereditary hemochromatosis is a genetic disorder featuring an iron overload of the body due to dysregulated iron absorption. The most common underlying gene defect is a 
mutation in the HFE (High Iron $\mathrm{Fe}$ ) gene with autosomal recessive inheritance termed 'classic' adult hemochromatosis. About $90 \%$ of the patients are homozygous for the C282Y mutation in the HFE gene with a prevalence of about 5:1,000 [1]. 5\% of hemochromatosis patients are 'compound heterozygous' for the C282Y mutation with a H63D (or rarely a S65C) mutation on the other allele. Due to low penetrance, only up to about $25 \%$ of homozygous genetic carriers develop clinically manifest hemochromatosis [2]. Patients with a compound heterozygous mutation have a lower risk of iron accumulation in comparison to homozygous patients.

The HFE protein regulates the iron storage hormone hepcidin. Due to dysfunction of the HFE protein, hepcidin is downregulated. This leads to an upregulation of ferroportin, a transmembranous protein that transports iron from the intra- to the extracellular space. Therefore, iron absorption in the gut is enhanced due to increased iron release from basal enterocytes. As a consequence of increased iron uptake, iron accumulation leads to tissue damage. Typical clinical signs of iron overload are fatigue, joint pain, liver cirrhosis and cancer, diabetes and hyperpigmentation of the skin ('bronze diabetes'), or secondary cardiomyopathy [3]. The typical age of clinical manifestation of HFE hemochromatosis is about midlife in men, with delayed manifestation in women, due to iron loss through menstrual bleeding [2].

The diagnosis of idiopathic hemochromatosis is made by elevated ferritin levels (above $\approx 250 \mu \mathrm{g} / \mathrm{l}$ ), elevated transferrin saturation (>45\%), HFE gene diagnostic and liver biopsy [3]. Because ferritin is an inflammatory marker, elevated ferritin levels are also seen in metabolic syndrome. However, transferrin saturation is normal in these patients [3]. Excessive alcohol consumption can also cause iron overload [4].

Repeated phlebotomy is the therapy of choice to empty the iron deposits. The therapeutic aim is a ferritin level of $<50 \mu \mathrm{g} / \mathrm{l}[5]$.

Total hemoglobin mass $(\mathrm{tHb})$ is the sum of all hemoglobin in the body. In contrast to hemoglobin concentration $([\mathrm{Hb}])$, it is independent from plasma volume. The main predictor of tHb is lean body mass (LBM) [6], but it can be increased, i.e. by endurance training or altitude exposure. It is a determinant of the oxygen-carrying capacity of the blood and therefore influences the maximum oxygen consumption $\left(\mathrm{VO}_{2 \max }\right)$ [7].

In hemochromatosis patients, iron uptake also seems to be increased in erythropoietic progenitor cells [8], where it is bound in hemoglobin. Hence, elevated erythrocyte indices $\mathrm{MCV}, \mathrm{MCH}, \mathrm{MCHC}$ and $[\mathrm{Hb}]$ have been observed $[8,9]$.

tHb has not been studied in hemochromatosis patients. With this case, we report tHb during depletion of iron stores through repeated phlebotomies at initially elevated iron deposits.

\section{Case Presentation}

\section{Subject and Diagnostics}

The 52-year-old Caucasian male leisure time runner (height $179 \mathrm{~cm}$, training load 1-2 h per week, for further anthropometric characteristics see table 1) presented to our institute for a preventive checkup with a significantly elevated ferritin value $(1,276 \mu \mathrm{g} / \mathrm{l}$, fig. 1$)$. No previous disease was known and the subject did not take any medication. Diagnosis of hemochromatosis was made by an elevated transferrin saturation (58\%, table 1) and HFE gene diagnostics (63HD/282CY, compound heterozygote). Liver biopsy showed a slightly elevated iron content of the liver $(2,646 \mu \mathrm{g} / \mathrm{g}$ ), a slight siderosis (stage 1) and a slight fibrosis (stage 
1C). Additionally, the diagnosis of NASH (alcohol consumption about $50 \mathrm{~g} /$ day, four times per week) and type II diabetes mellitus was made (HbA1C 6.2\%, fasting glucose $153 \mathrm{mg} / \mathrm{dl}$ ). The diagnosis of a metabolic syndrome was made based on increased waist circumference $(95 \mathrm{~cm}$ ) and the presence of arterial hypertension (blood pressure 140/90 $\mathrm{mm} \mathrm{Hg}$ ), based on the IDF criteria [10]. hsCRP was normal (2.66 mg/l).

The subject did not report any symptoms at the time of the diagnosis. The family history was unremarkable for hemochromatosis or elevated ferritin levels.

No medication was started after the diagnosis had been established. However, dietary recommendations were made (nutrition poor of iron and suitable to diabetes). The subject did not manage to reduce alcohol consumption under $15 \mathrm{~g} /$ day, 3 times per week.

The application of the CO-rebreathing method was approved by the institutional ethics committee at the University of Freiburg, Freiburg, Germany. Written informed consent was obtained from the subject before follow-up.

\section{Therapy and Follow-Up}

Therapeutic phlebotomy was started 2 months after diagnosis of hemochromatosis. 500 or $1,000 \mathrm{ml}$ of whole blood were withdrawn every 1-5 weeks, respectively (fig. 1). Before each therapeutic phlebotomy $\mathrm{tHb}$, body weight and resting heart rate, as well as a laboratory profile were determined. Body composition was determined by densitometry (Bod Pod, Life Measurement, Inc., USA) in study week 1, 18 and 71. After having reached a normal ferritin level, the subject received a maintenance therapy with a recommended phlebotomy interval of every 2-4 months. The general condition and physical performance were regularly followed up to evaluate the response to therapy.

\section{Determination of $t \mathrm{Hb}$}

tHb was determined as described by Schmidt and Prommer [11] by the optimized COrebreathing method. We used a standard spirometer (Spico-CO Respirations-Applikator, Universität Bayreuth, Bayreuth, Germany). Carboxyhemoglobin content was determined with an OSM 3 Hemoximeter (Radiometer, Copenhagen, Denmark).

\section{Calculations}

The loss of $\mathrm{tHb}\left(\mathrm{tHb}_{\text {loss }}\right)$ through each phlebotomy was calculated from current $[\mathrm{Hb}]$ and the volume of blood withdrawn.

The reproduction rate of $\mathrm{tHb}$ per day $\left(\mathrm{RR}_{\mathrm{tHb}}\right)$ was calculated as follows:

$\mathrm{RR}_{\mathrm{tHb}}(\mathrm{g} /$ day $)=\left[\mathrm{tHb}_{\text {loss }}+\left(\mathrm{tHb}_{\text {actual }}-\mathrm{tHb}_{\text {last }}\right)\right] \times\left[\text { date }_{\text {actual }}-\text { date }_{\text {last }}(\text { days })\right]^{-1}$

Peak oxygen consumption $\left(\mathrm{VO}_{2 \text { peak }}\right)$ was inferred from treadmill incremental exercise testing according to the formula as proposed by the American College of Sports Medicine [12]:

$\mathrm{VO}_{2 \text { peak }}(\mathrm{ml} / \mathrm{min} / \mathrm{kg})=(0.2 \times \mathrm{S})+(0.9 \times \mathrm{S} \times \mathrm{G})+3.5 \mathrm{ml} / \mathrm{min} / \mathrm{kg}$

where $\mathrm{S}=$ speed and $\mathrm{G}=$ percent grade expressed as fraction.

\section{Outcome}

The subject was followed for 91 weeks since the initiation of therapy. The therapeutic target of ferritin was reached after 10 phlebotomies, equivalent to $7.5 \mathrm{l}$ of whole blood, in study week 26 (53 $\mu \mathrm{g} / \mathrm{l})$ (fig. 1). During the whole study course, 14 phlebotomies were conducted, equivalent to $9.5 \mathrm{l}$ of whole blood. Before therapy, tHb was $847 \mathrm{~g}$. After an initial decline to a minimal tHb of $718 \mathrm{~g}$, tHb was reestablished during therapy, with a maximum $\mathrm{RR}_{\mathrm{tHb}}$ of $10.8 \mathrm{~g} /$ day (table 1 ). tHb reached the pretherapy level in week 10 after 6 phleboto- 
mies. At the end of follow-up and during maintenance therapy, tHb was not lower than before therapy (837 $\mathrm{g}$ in week 91) (fig. 1).

[Hb] did not decline to anemic levels at any time during therapy (table 1). Body weight, LBM and BMI were essentially unchanged between the beginning and the end of therapy.

The subject did not report any adverse events during therapy. Subjectively, physical performance was not affected during maintenance therapy. $\mathrm{Vo}_{2 \text { peak }}$ was unaltered (49.8 $\mathrm{ml} / \mathrm{min} / \mathrm{kg}$ ) in study week 91 compared to before therapy.

\section{Discussion}

The main finding of this case report was that, after therapeutic depletion of iron stores, tHb was not reduced compared to the level before therapy (fig. 1). The therapeutic aim of phlebotomy in hemochromatosis is a ferritin level $<50 \mu \mathrm{g} / \mathrm{l}$ [5]. Our findings suggest that, in contrast to a situation with iron deficiency [13], tHb is not permanently reduced in this hemochromatosis patient during or after therapeutic phlebotomy as long as the body iron stores are in the normal range.

The initially elevated iron content in the body does not seem to be associated with an increased tHb. This has already been hypothesized by Barton et al. [8] by calculating the additional amount of hemoglobin in hemochromatosis patients from standard hematologic parameters. Calculation of the additional hemoglobin from these parameters, which are dependent on plasma volume, pointed towards an additional amount of circulating hemoglobin of only approximately $5 \mathrm{~g}$ [8]. Through the application of the CO-rebreathing method, we were now able to quantify tHb directly and independently from plasma volume. Our measurements support their calculation [8], highlighting a negligible elevation of tHb from a clinical point of view.

Here it is of note that the strongest predictor of tHb is LBM. LBM was determined during the course of therapy and remained unchanged. $\mathrm{VO}_{2 \text { peak, }}$ a parameter for aerobic capacity, also remained unchanged during maintenance therapy. This is consistent with a normal subjective physical performance of the patient throughout the study. As hsCRP was normal in our patient, hyperferritinemia due to metabolic syndrome can be excluded.

Interestingly, in our patient, tHb was already reestablished during the initial 10 weeks of bloodletting and the reproduction rate of tHb during the phlebotomy period was very high. Pottgiesser et al. [14] showed that a tHb loss of $81 \mathrm{~g}$ after donation of about $550 \mathrm{ml}$ of whole blood was regenerated after $36 \pm 11$ days, corresponding to an $\mathrm{RR}_{\mathrm{tHb}}$ of $2.25 \mathrm{~g} /$ day, in normal persons. The maximum $R_{\mathrm{tHb}}$ in our case was $10.8 \mathrm{~g} /$ day (table 1 ). This is about five times more than in the average subjects observed by Pottgiesser et al. This enhanced erythropoiesis could be attributed to the increased iron offer and delivery to the erythropoietic progenitor cells. This hypothesis might be supported by the observation that production of $\mathrm{tHb}$ is increased after altitude exposure and oral supplementation of high amounts of iron in comparison to altitude exposure without or low amounts of iron supplementation [15].

\section{Conclusion}

In this hemochromatosis patient, tHb seems not to be elevated at the time point of diagnosis in a state of elevated body iron content. After an initial decline of tHb of about $15 \%$ with therapeutic phlebotomy, tHb was reestablished between weeks 4 and 10 and remained 
Wrobel et al.: Therapeutic Depletion of Iron Stores Is Not Associated with a Reduced Hemoglobin Mass in a Hemochromatosis Patient

stable despite further bloodletting, demonstrating an accelerated erythropoiesis. This might possibly be explained by an elevated iron supply.

\section{Acknowledgements}

The article processing charge was funded by the German Research Foundation (DFG) and University of Freiburg in the funding program Open Access Publishing. We thank the patient for the agreement with the measurements of tHb during follow-up. We also thank the patient for the consent to the publication of the material.

\section{Statement of Ethics}

The application of the CO-rebreathing method was approved by the institutional ethics committee at the University of Freiburg, Freiburg, Germany. Written informed consent was obtained from the subject before follow-up.

\section{Disclosure Statement}

The authors declare that they have no competing interests.

\section{References}

1 Adams PC, Reboussin DM, Barton JC, et al: Hemochromatosis and iron-overload screening in a racially diverse population. N Engl J Med 2005;352:1769-1778.

- Gallego CJ, Burt A, Sundaresan AS, et al: Penetrance of hemochromatosis in HFE genotypes resulting in p.Cys282Tyr and p. [Cys282Tyr]; [His63Asp] in the eMERGE Network. Am J Hum Genet 2015;97:512520.

-3 Bacon BR, Adams PC, Kowdley KV, Powell LW, Tavill AS: Diagnosis and management of hemochromatosis: 2011 practice guideline by the American Association for the Study of Liver Diseases. Hepatology 2011;54:328-343.

-4 Ioannou GN, Dominitz JA, Weiss NS, Heagerty PJ, Kowdley KV: The effect of alcohol consumption on the prevalence of iron overload, iron deficiency, and iron deficiency anemia. Gastroenterology 2004;126:1293-1301.

5 Adams PC, Barton JC: How I treat hemochromatosis. Blood 2010;116:317-325.

-6 Schumacher YO, Ahlgrim C, Pottgiesser T: Evaluation of anthropometrical reference parameters for hemoglobin mass in endurance athletes. J Sports Med Phys Fitness 2008;48:509-514.

7 Schmidt W, Heinicke K, Rojas J, et al: Blood volume and hemoglobin mass in endurance athletes from moderate altitude. Med Sci Sports Exerc 2002;34:1934-1940.

-8 Barton JC, Bertoli LF, Rothenberg BE: Peripheral blood erythrocyte parameters in hemochromatosis: evidence for increased erythrocyte hemoglobin content. J Lab Clin Med 2000;135:96-104.

-9 McLaren CE, Barton JC, Gordeuk VR, et al: Determinants and characteristics of mean corpuscular volume and hemoglobin concentration in white HFE C282Y homozygotes in the hemochromatosis and iron overload screening study. Am J Hematol 2007;82:898-905.

10 Zimmet P, Magliano D, Matsuzawa Y, Alberti G, Shaw J: The metabolic syndrome: a global public health problem and a new definition. J Atheroscler Thromb 2005;12:295-300.

11 Schmidt W, Prommer N: The optimised CO-rebreathing method: a new tool to determine total haemoglobin mass routinely. Eur J Appl Physiol 2005;95:486-495.

12 Glass S, Gregory B: ACSM's Metabolic Calculations Handbook. Baltimore, Lippincott Williams and Wilkins, 2007.

13 Wachsmuth NB, Aigner T, Völzke C, Zapf J, Schmidt WF: Monitoring recovery from iron deficiency using total hemoglobin mass. Med Sci Sports Exerc 2015;47:419-427. 
14 Pottgiesser T, Specker W, Umhau M, Dickhuth H-H, Roecker K, Schumacher YO: Recovery of hemoglobin mass after blood donation. Transfusion (Paris) 2008;48:1390-1397.

15 Govus AD, Garvican-Lewis LA, Abbiss CR, Peeling P, Gore CJ: Pre-altitude serum ferritin levels and daily oral iron supplement dose mediate iron parameter and hemoglobin mass responses to altitude exposure. PloS One 2015;10:e0135120.

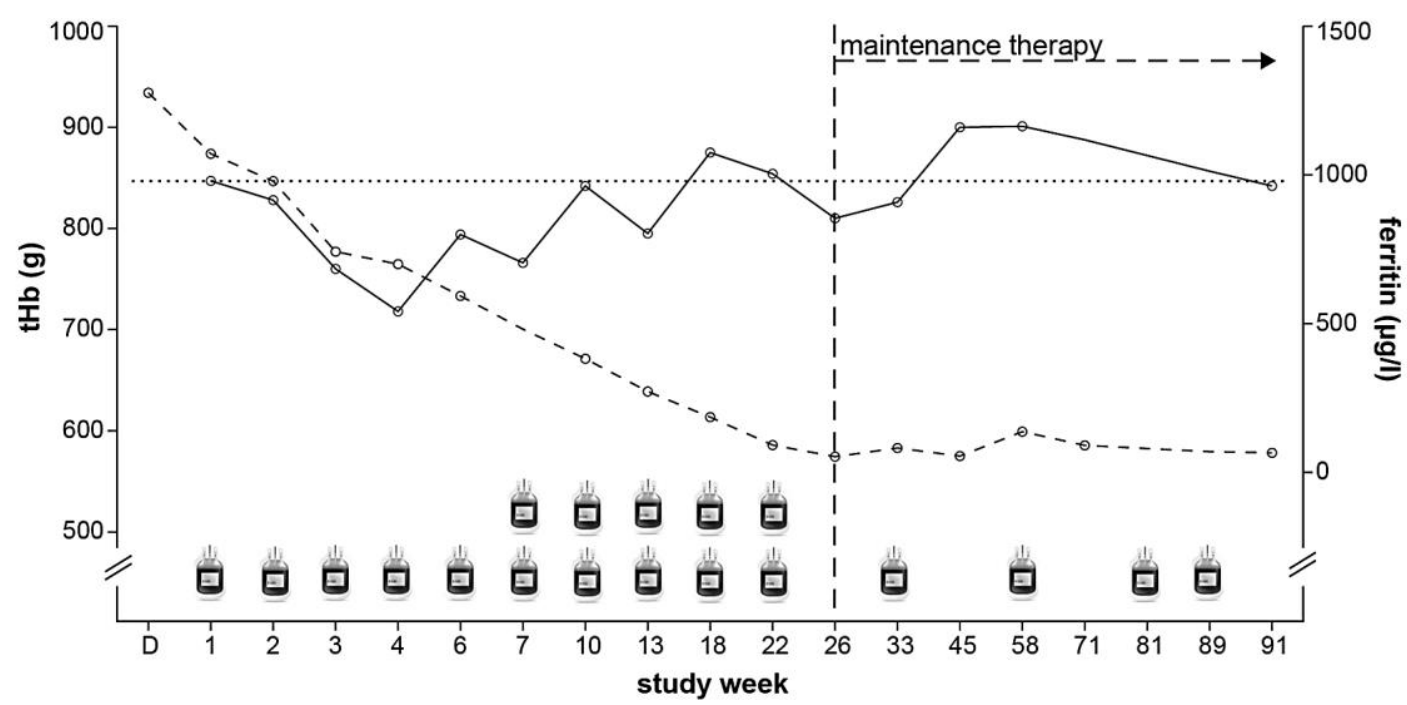

Fig. 1. Time course of therapeutic phlebotomies, thb and ferritin.

$=$ Phlebotomy of $500 \mathrm{ml}$ of whole blood; $\mathrm{D}=$ day of diagnosis; solid line = trend of $\mathrm{tHb}$; dashed line = development of ferritin; horizontal dotted line = level of tHb before therapy; vertical dashed line = achieved therapeutic target of ferritin. 


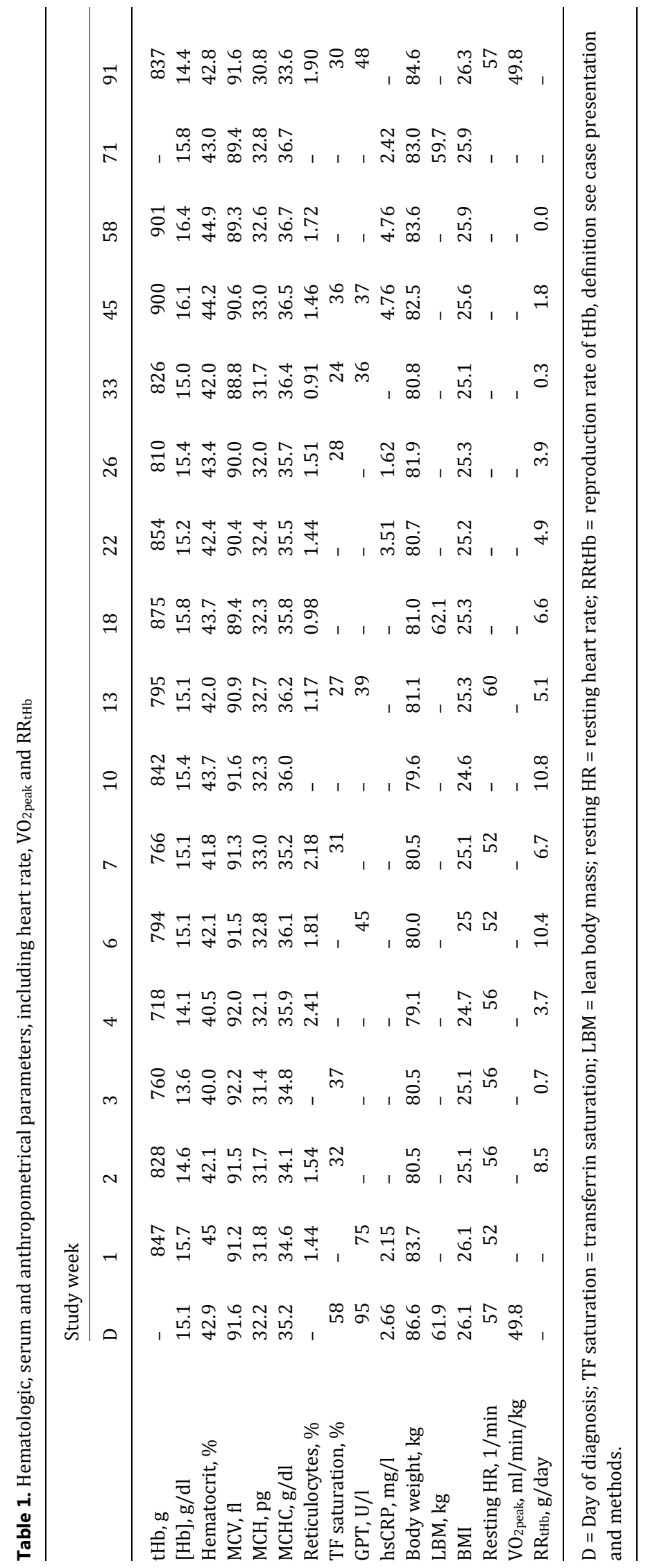

